\title{
A colonização digital do isolamento
}

\author{
JEAN SEGATA \\ Universidade Federal do Rio Grande do Sul, Porto Alegre, Rio Grande do Sul, Brasil \\ jeansegata@ufrgs.br
}

DOI 10.11606/issn.2316-9133.v29i1p163-171

"Chega, chega”, ela digitou no chat antes de sair da sala do MConf no meio da discussão de uma pauta. Com preocupação, alguns de nós buscamos contato no grupo da comissão, no WhatsApp. "O que aconteceu?", alguém perguntou. "É minha terceira reunião hoje. A gente sai de uma e emenda outra. Enlouquecedor isso tudo", explicou. "Tô com vocês aqui e ao mesmo tempo com um outro pessoal no Zoom", completou com um emoji de choro. Voltamos para a reunião e seguimos com a pauta, lamentando a carga de novas demandas impostas pelo tempo da pandemia. A conexão era ruim, o som “cortava”, e tudo demorava ainda mais tempo. Quando algum microfone era aberto, ouviam-se os sons da casa - o ruído de panelas, a TV, cães latindo ou crianças brincando. A tarde seguiu, e cada vez que "alguém caía”, mandava uma mensagem no whats pra avisar que estava tudo bem e que já voltaria ao encontro.

A situação era localizada. Em parte, ela ecoava uma rotina comum entre muitos docentes e técnicos que além do ensino, da pesquisa e da extensão, também se envolvem em atividades administrativas da universidade. No entanto, com a suspensão das atividades presenciais em virtude da Covid-19 e a exigência do trabalho como home office, novos desafios têm ganhado contorno. $\mathrm{O}$ episódio relatado, assim, não parece uma exceção. $\mathrm{O}$ chamado isolamento social, estimulado como modo de mitigação do agravamento dos índices de contágio, tem posto em relevo inúmeras experiências de desgaste com as atividades remotas em meios digitais. Participantes de redes sociais na internet relatam com frequência as suas dificuldades em gerir o tempo do lazer, do descanso e da privacidade, com aquele do trabalho ou da escola online dos seus filhos. Na opinião pública e entre especialistas, também aumenta a preocupação com a precarização do trabalho e com a saúde mental de quem se expõe a estas novas práticas ${ }^{1}$.

\footnotetext{
${ }^{1}$ A precarização do trabalho é um dos eixos do estudo que coordeno por meio da Rede COVID-19 Humanidades, intitulada A Covid-19 no Brasil: análise e resposta aos impactos sociais da pandemia entre profissionais de saúde e população em isolamento. A pesquisa responde a uma encomenda do Ministério da Ciência, Tecnologia, Inovações e
} 
Não há dúvidas de que este não é único problema que temos vivido com a pandemia. Há inúmeros cenários de injustiça, de desigualdade, de dor e de perdas que ela provoca ou intensifica. Eles são desafiadores - seja para quem os vive ou para quem deseja compreendê-los em suas pesquisas. No entanto, enquanto eu pensava em como reagir ao convite para escrever sobre a Covid-19 nesta Seção Conjuntura da Cadernos de Campo, o episódio da reunião me afetou. Faz alguns anos que eu me interesso pelas relações entre humanos, computadores e outros dispositivos conectados à internet. Numa fórmula sintética, o digital e os seus processos de subjetivação e de produção da vida. Em si, a pandemia pouco tem a ver com isto. Mas situações críticas que ela provoca, como a do isolamento social, parecem induzir ainda mais o uso de dispositivos conectados à internet. Os efeitos desse processo podem ser um terreno particularmente fértil para reflexões antropológicas sobre constituição de sujeito e sobre o contemporâneo. Neste trabalho, eu apresento situações que conectam aspectos do trabalho docente, do isolamento e o digital para tornar saliente uma maquinaria silenciosa que articula conforto e segurança com produtivismo e sofrimento.

\section{Windows de oportunidade}

"A tela desliga do nada e, às vezes, aparecem umas mensagens de erro, um xis vermelho, e aí eu penso: pronto, estraguei. Eu fico com medo”, revelava a professora. A queixa parece de hoje, mas tem mais quinze anos. Eu a pincei das páginas impressas e amareladas que resultaram do meu primeiro trabalho de campo - apesar do digital, foi a materialidade do papel que resistiu, mais do que a dos disquetes e dos $C D s$ de back up, obsoletos com o passar do tempo. Foi uma experiência etnográfica em um laboratório de informática de uma escola pública, no interior de Santa Catarina. Era 2003, eu terminava a graduação em Psicologia e estava interessado na produção de subjetividade na relação humano-computador em situações de ensinoaprendizagem (SEGATA, 2004).

No início dos anos 2000, poucas pessoas tinham acesso a internet no Brasil dos interiores. Havia uma infraestrutura de rede limitada, frequentemente discada, e os computadores eram muito caros. Com promessas de inclusão digital e de modernização do ensino, o governo do Estado de Santa Catarina instalou salas de informática com internet 2.0. O objetivo era aprimorar competências para o século XXI. Os alunos da escola ficaram muito excitados com a possibilidade de usar computadores com o novo Windows 2003 e navegar na

Comunicações - MCTIC (Convênio Ref.: 0464/20 FINEP/UFRGS), sobre os “impactos sociais do coronavírus”. Nela, temos explorado a expansão do "capitalismo de plataformas", como no caso das chamadas uberização e homeoficização das relações de trabalho (ROSENBLAT, 2018; MUNIZ, 2020). Como mais um desdobramento do modo como atuam as tecnologias digitais no cotidiano, elas formam duas faces destacadas de uma infraestrutura precária do isolamento social no tempo da pandemia, que envolve o cálculo do cuidado, mas também o risco e o sofrimento. 
internet a cabo. Mas, alguns professores diziam que essas coisas eram uma utopia da classe média americanizada - fingiam inclusão, enquanto, na verdade, exigiam a adesão compulsória a um novo modelo de vida e de educação. "Imagina, a gente já dá aulas o dia inteiro e no turno da noite. Trabalho em duas escolas. Corrijo prova, preparo atividade. Quando é que eu vou ter tempo pra fazer cursinho de informática?”, reclamava a professora de Educação Artística. “Diz que vai facilitar, que vai facilitar. Aham. Eu tenho muita vergonha. Não cresci grudada num computador. Mal sei ligar, e entrar na internet. Eu fico apanhando na frente da turma”, continuava. Naquela época, a escola recebia os computadores com as promessas de inovação educacional, mas ainda não dimensiona o quanto computadores e internet exigiriam, de forma acelerada, novos, complexos e contínuos processos de aprendizagem (TURKLE, 2015; LEITÃO et al, 2019). Sobretudo, ficava evidente que quem mais precisava aprender a manejar a máquina eram os professores, que liam essa demanda na chave de mais carga de trabalho não contabilizado. A direção da escola contra-argumentava dizendo que era uma oportunidade de se atualizar e de fazer render o tempo, com as facilidades que o computador e a internet ofereciam para maximizar a produtividade.

Carvalho (2000), em sua pesquisa com profissionais da educação e do serviço público, já problematizava as novas configurações de sujeito adequadas à rentabilidade do tempo. Setores que operavam cálculos nos meados dos anos de 1990 passavam a ver o seu fluxo operacional se multiplicar: o inventário de um estoque ou a operação contábil que levava alguns dias passou a ser feita em horas. Muito mais em menos tempo virou a métrica do trabalho baseado em tecnologia digital. Neste processo, a sensação contínua de desatualização e incompetência, o sentimento de humilhação e ridicularização e o medo e a irritação provocada pela dificuldade de "acompanhar o ritmo da máquina”, eram algumas das queixas mais frequentes levantadas pelo autor e que revelavam novos modos de sofrimento laboral, sobretudo entre docentes. Houve, como relata um dos seus sujeitos de pesquisa, um longo percurso de invenção de maneiras de driblar a máquina, mas também de pensar como ela e entender o que ela exigia (CARVALHO, 2000) ${ }^{2}$.

A sobrecarga de trabalho, acentuada pela nova responsabilidade tinham que assumir com o aprendizado informático, correspondia também a uma queixa frequente na minha pesquisa com professores, e vinha acompanhada de outras mais. Como eu costumava ouvir, ao invés do prometido suporte, computadores e internet promoviam ansiedade, cansaço mental e um sentimento de incerteza, submissão e perda. "A escola vai virar uma linha de produção. Logo

\footnotetext{
${ }^{2}$ Interessante pontuar que havia uma preocupação latente nos anos de 1980 sobre os efeitos dos computadores no desenvolvimento de crianças e nos processos de ensino-aprendizagem, de forma mais ampla. Na época, um debate complexo e que orientava a análise de Carvalho (2000) se constituía em torno da chamada inteligência artificial. Sobre ela, Sherry Turkle, se perguntava se inteligência artificial seria o caso de computadores pensarem como gente (TURKLE, 1984). O que ela mesma explorou por diferentes caminhos desde três décadas é que, nessa digitalização da vida, foi a gente que passou a pensar (e agir) como computadores (TURKLE, 2015).
} 
vão botar um robô no nosso lugar”, dizia um professor de História. A crítica que corria era a de que queriam substituir Piaget e Vigotsky pelo Bill Gates, o mais rápido possível (Segata, 2004). Neste sentido, outro ponto saliente daquela experiência na escola era a queixa de que a tão indispensável inclusão digital era apenas voltada para estudantes e não para professores. Muitos não se sentiam preparados para atuar naquele novo ambiente forjado pelas chamadas TICs Tecnologias de Informação e Comunicação. Resultava que a "sala de informática" não era incorporada ao cotidiano das suas aulas como uma ferramenta que potencializasse o processo de ensino-aprendizagem com a oferta de alternativas para a expansão dos conteúdos ou mesmo de "inovação dos currículos escolares", como era sugerido pelo governo. Ela foi convertida, em grande medida, em um espaço de lazer. Se a turma "se comportasse bem", poderiam, como prêmio, "ir para informática" para entrar na internet ou simplesmente para brincar no paintbrush ou jogar Doom no MS-DOS (SEGATA, 2004).

Importa também dizer que não é sem razão que eu tenho grifado a expressão entrar na internet. Na época, havia a uma certa sensação partilhada de que ela estava em algum lugar e que nela, estava o mundo: novos lugares, novos amigos, sair, acelerar, ir para longe - uma janela de oportunidades ${ }^{3}$. Era o tempo de uma promessa ufanista de que computadores conectados em rede permitiriam a desterritorialização e a múltipla presença, e isso tensionava as relações na escola. Havia produção de subjetividades na relação com as máquinas - medo de operá-las, desconfiança com seus propósitos imperialistas, mas também os conflitos geracionais. É que os estudantes, mas também alguns jovens professores, queriam "sair do isolamento" e a rede mundial de computadores era uma promessa de liberdade. Para eles, não era mais possível ficar parado no tempo e no espaço, desconectados. As habilidades para o novo século, inculcadas no projeto da "sala de informática", apontavam para a formação um novo tipo de sujeito-profissional empreendedor, cosmopolita e multi-competente. Para isso acontecer, não era mais possível continuar vivendo como um analfabeto digital, distante do mundo, preso num passado offline. Afinal, o que seria daqueles jovens do interior sem as oportunidades de emancipação que a rede abria simultaneamente em cada "janela do Windows"? A ubiquidade da internet era uma esperança de futuro e de transformação (SEGATA, 2004). Acontece que o el dorado do estar em

\footnotetext{
${ }^{3}$ O filósofo Pierre Lévy foi uma referência emblemática para a constituição deste debate. São inúmeras as suas contribuições sobre as potencialidades de computadores e internet para a educação e o desenvolvimento humano. Uma ideia saliente na sua obra era a de inteligência coletiva, entendido como sendo distribuída, em tempo real, mobilizando competências conectadas (LÉVY, 2003). O filósofo é, digamos assim, representativo entre os "ufanistas" da internet. O debate na época era polarizado entre estes entusiastas da nova tecnologia, que viam nela democratização, emancipação e expansão das capacidades humanas e os pessimistas, que vinham nela simulacrado, afastamento e hiperindividualização (BAUDRILLARD, 2003). Para uma síntese desta discussão e as alternativas antropológicas que se constituíam, ver Segata et al (2011).
} 
muitos lugares e fazendo tantas coisas ao mesmo tempo já apresentava efeitos colaterais antes mesmo das promessas de formar a gente do Século XXI.

\section{A economia temporal da ubiquidade, ontem e hoje}

Em um artigo publicado em 1996, o sociólogo Francis Jauréguiberry analisava a complexidade da simultaneidade permitida pelos telefones móveis portáteis. Os telefones do início do século XX já haviam introduzido o poder de se "estar aqui e em outros lugares ao mesmo tempo", ao menos falando e ouvindo a partir de pontos fixos, como escritórios, cabines públicas ou residências. Contudo, os novos dispositivos móveis introduziam um sabor intenso à experiência da onipresença, pois "eles permitem que você esteja fisicamente onde está e ao mesmo tempo onde deseja” (JAURÉGUIBERRY, 1996, p. 01, minha tradução). Mas, a ubiquidade é uma via de mão dupla. Ela expande experiências de subjetividade, corporalidade, comunicação e relação de indivíduos e de coletividades, mas também potencializa o capitalismo e seus meios de exploração. É por isso que para o autor, era preciso analisar com mais cuidado a aceleração e o desdobramento do tempo e o modo como eles introduziam novas modalidades do já frequente utilitarismo investido no aprimoramento de ferramentas tecnológicas.

Jauréguiberry (1996) analisa o emprego de celulares entre uma minoria de executivos de grandes corporações que já tinham acesso a este tipo de tecnologia no início dos anos de 1990. Ele observa que nos interstícios do "tempo ocupado", aquele, por exemplo, do deslocamento da casa até o trabalho, já não era mais "vazio". Executivos começavam a "aproveitar" este tempo organizando a agenda do dia com a sua secretaria. Respondiam a questões breves, introduziam ou adiavam compromissos conforme novas urgências e interesses apareciam. Para Jauréguiberry (1996), na visão destes executivos, o telefone celular capitalizou o "tempo morto". Mas, o que começava a se tornar crítico era o fato de que, à despeito de o tempo poder ser, desde sempre, desdobrado mentalmente, agora ele o era fisicamente. Estar em um determinado lugar e, ao mesmo tempo, imaginar estar em outro, não era novidade. Mas, para o autor, era preciso avaliar os efeitos da simultaneidade permitida pelos aparatos digitais: estar em casa, no carro ou no trem e, ao mesmo tempo, no escritório despachando.

$\mathrm{Na}$ linha de pensamento de Jauréguiberry (1996), a sobreposição do tempo começava a ser incorporada como um hábito de resposta ao sempre urgente, à velocidade das respostas às demandas do mercado, como uma regra de sobrevivência no mundo contemporâneo. Uma espécie de "tirania do imediato" passou a se estender a todos os setores da vida profissional. A sensação que emergiu foi a de que a sua recusa fosse convertida numa condenação à marginalidade do mundo. Era o gatilho para o que o autor chamou de síndrome do zapeador - um conjunto de sintomas do mal latente que acomete quem vive a experiência de onipresença, da participação e do consumo de informação em um tempo acelerado e desdobrado, a ponto de ser absorvido. Na nova economia temporal, facilitada pelas tecnologias digitais, prevalece 
a ansiedade do tempo perdido e a do último momento, o desejo nunca satisfeito de estar aqui e em outros lugares ao mesmo tempo, o medo de perder algo importante e não ser capaz de fazer tudo, o estresse das escolhas precipitadas e a insatisfação resultante delas, a confusão causada pelo excesso de informações efêmeras, a tensão entre uma crescente instrumentalização do relacionamento com os outros e a busca de sentimentos profundos (JAURÉGUIBERRY, 1996, p. 175, minha tradução).

"Abre a câmera", "desliga o microfooooone", "eu não sei mexer nisso". As reuniões de trabalho têm continuado, com as novas competências exigidas. Quase sempre dão certo, mas algumas plataformas complicam as coisas: os arquivos partilhados são incompatíveis, alguns dispositivos operam com sistemas operacionais diferentes ou não oferecem as mesmas funções para computadores, tablets e smartphones. É Zoom, Meet, Skype, Hangout, Jitsi. Os encontros frustam e aborrecem. Entre sons cortados e negociação das etiquetas e aprendizado de uso das plataformas, eles ocupam o dia, algumas vezes, sobrepostos. Mas, estamos em casa, "temos tempo", então resta otimizar o isolamento.

"Enlouquecedor isso tudo". A queixa que me afetou no episódio da reunião ecoa um conjunto de sentimentos que não é novo e que tem sido partilhado entre estudantes, docentes e técnicos. Traduzidos na gramática do adoecimento mental, sobretudo da depressão, eles começam a ganhar espaço no debate público em meios acadêmicos. Em foco, o esgotamento resultante das inúmeras tensões e ansiedades constituídas em torno de uma vida acadêmica competitiva - do genial, do criativo e do multifuncional. É, digamos assim, uma prestação de contas com aquele investimento high-tech de uma "pedagogia Bill Gates", do qual me falavam naquela experiência etnográfica na escola. Ela nos "resgatou" do analfabetismo digital e do "isolamento offline". Agora, precisamos responder com a produtividade que colonizou a universidade, naquilo que Shore e Wright (2000) chamaram de "cultura da accountability": participar de múltiplas reuniões em uma tela, potencializar o tempo da leitura através da “exposição dinâmica à informação" na outra, e acelerar o tempo da escrita, porque o fator de impacto não é amigo da ideia madura.

Como a situação epidemiológica da Covid-19 ainda aponta para níveis perigosos de contaminação, com altas taxas de ocupação hospitalar e elevado número de mortes diárias, a tendência é que o trabalho remoto continue, inclusive com aulas na universidade. Muitas destas reuniões da têm a ver com isso. $\mathrm{Na}$ pauta tem estado a adaptação emergencial do ensino presencial para o formato remoto. Em alguma medida, elas valorizam as experiências virtuosas já consolidadas no terreno do Ensino a Distância - EaD. Mas, na maioria dos casos, confundem educação com as lógicas neoliberais do "glamourizado" home office. "Não se pode parar", 
sobretudo, com "tantas facilidades que a tecnologia oferece". A pandemia suspendeu os calendários, "mas pode ser uma janela de oportunidades para a universidade definitivamente entrar no século XXI", ouvi alguém dizer em um fórum público, no Google Meet, antes da sua conexão, ironicamente, cair. São as estruturas de desigualdade funcionando para o favorecimento de quem pode ficar em casa com acesso aos bens e serviços dos dispositivos conectados à internet. Não é por menos que o digital anda de mãos dadas com a meritocracia e com a exclusão. Mas isso é pauta para outras agendas de debate que se abrem nesta conjuntura.

Enfim, como eu procurei mostrar neste trabalho, pouco a pouco e por diferentes caminhos, a produtividade e a rentabilidade sustentadas pelo digital foram silenciosamente normalizadas nos ambientes educacionais. Com a Covid-19 e as medidas de isolamento social, esse processo têm ganhado novos relevos. Ao facilitar uma infraestrutura para o trabalho remoto educacional, o digital sugere saúde e cuidado, evitando o agravamento da pandemia por meio da exposição ao vírus na rua. De outro, ela adoece, ao expandir e complexificar uma nova ordem de apelo utilitarista baseada na otimização do tempo dentro de casa. Além disso, o fetiche tecnocrático do tempo real que inculcou culpa no ócio, no cuidado se si, no respeito ao tempo da saúde e da doença, garante a outra parte do negócio. Ninguém fica parado sem a sensação de dívida. É preciso executar múltiplas tarefas: responder, informar, se manter inundado de atividades que maximizem o rendimento. $\mathrm{O}$ isolamento social hiperconectado intensifica a "vida nervosa" com a brutalidade de sua velocidade e variedade de estímulos, disfarçando um processo sutil de colonização digital, mas também de adoecimento individual e coletivo (MUNIZ, 2020).

Como nos concluiu a colega de trabalho no grupo do WhatsApp depois daquele episódio da reunião, "isso não para. Eu não aguento mais. A gente fica conectada o tempo todo. Eu só queria desligar e sair". Sobrecargas de trabalho, pressão produtivista e incertezas sobre o futuro, são uma combinação nociva. A homeoficização da vida acadêmica adoece, sobretudo quanto quer otimizar o tempo da pandemia.

\section{Referências Bibliográficas}

BAUDRILLARD, Jean. (2003). Tela Total: mito-ironias do virtual e da imagem. 3.ed. Porto Alegre: Sulina.

CARVALHO, Paulo Sérgio de. (2000). Interação entre humanos e computadores: uma introdução. São Paulo: Educ.

ESCOBAR, Arturo. (2016). "Bem-vindos à Cyberia: notas para uma antropologia da cibercultura”. In SEGATA, Jean \& RIFIOTIS, Theophilos (ed.). Políticas etnográficas no campo da cibercultura. Brasília: ABA Publicações, p. 21-66.

FISCHER, Michael. (2003). Emergent forms of life and the anthropological voice. Durham: Duke University Press. 
HELMREICH, Stefan. (1998). Silicon second nature: culturing artificial life in a digital world. Oakland: California University Press.

JAURÉGUIBERRY, Francis. (1996). De l'usage des téléphones portatifs comme expérience du dédoublement et de l'accélération du temps. Technologies de l information et société, vol. 8, n. 2, Paris, p. 169-187.

LEITÃO, Débora et al. (2019). Pegando o jeito de domar o bicho: o processo de aprendizagem das tecnologias digitais por idosos. In: Revista de Antropologia, vol. 62, n. 3, São Paulo, p. 652-678.

LÉVY, Pierre. (2003). A inteligência coletiva: por uma antropologia do ciberespaço. 4. ed. São Paulo: Loyola.

MUNIZ, Carolina. (2020). Home office na pandemia pode levar profissionais à exaustão. Folha de São Paulo, São Paulo. Disponível em: < https://www1.folha.uol.com.br/sobretudo/carreiras/2020/04/home-office-na-pandemiapode-levar-profissionais-a-exaustao.shtml>. Acesso em 25 de maio de 2020.

RIBEIRO, Gustavo Lins. (2018). El precio de la palabra: la hegemonía del capitalismo electrónico-informático y el googleísmo. Desacatos, Cidade do México, vol. 56, p. 16-34.

ROSENBLAT, Alex. (2018). Uberland: how algorithms are rewrinting the rules of work. Oakland: California University Press.

SEGATA, Jean. (2004). Na fogueira on-line: uma etnografia da construção de subjetividade e sociabilidade na relação com as novas tecnologias pelos professores da Escola de Educação Básica Regente Feijó de Lontras/SC. Trabalho de Conclusão de Curso (Bacharelado em Psicologia) - Faculdade de Ciências Humanas, Linguagens e Artes, Universidade Para o Desenvolvimento do Alto Vale do Itajaí, Rio do Sul, 2004.

. (2008). Lontras e a construção de laços no Orkut: uma antropologia no ciberespaço. Rio do Sul, Nova Era.

. (2019). El mosquito-oráculo y otras tecnologías. In:Tabula Rasa, vol. 32, Bogotá, p. 103-125.

SEGATA, Jean et al. (2011). Admirável Mundo Novo: a cibercultura e os apocalípticos e apologéticos do ciberespaço. Revista Caminhos, vol. 2, n. 4, Rio do Sul, p. 17-26.

SHORE, Cris; WRIGHT, Susan. (2000). "Coercive accountability: the new audit culture and its impact on anthropology”. In: STRATHERN, Marilyn (ed.). Audit cultures: anthropological studies in accountability, ethics and the academy. London: Routledge: p. 57-89.

TURKLE, Sherry. The second self: computers and the human spirit. Cambridge: MTI Press. . (2015). Alone together: why we expect more from technology and less from each other. New York: Basic Books. 
sobre o autor

\section{Jean Segata}

é professor do Programa de Pós-Graduação em Antropologia Social, da Universidade Federal do Rio Grande do Sul, onde coordena o NEAAT - Núcleo de Estudos Animais, Ambientes e Tecnologias. É também mestre e doutor em Antropologia Social pela Universidade Federal de Santa Catarina.

\section{Recebido em 17/03/2020 \\ Aceito para publicação em 4/06/2020}

